\title{
RUTGERS CENTER OF ALCOHOL STUDIES LIBRARY: A BRIEF HISTORY
}

\author{
BY CATHERINE WEGLARZ
}

Ms. Weglarz is Librarian at the Rutgers Center of Alcohol Studies, New Brunswick, N.J.

\begin{abstract}
1 LCOHOL STUDIES requires a multidisciplinary approach to $A$ all aspects of beverage alcohol use and abuse, including alcohol1 ism. Rutgers Center of Alcohol Studies maintains a unique position in our society's efforts to understand this complex field. The Center's mission has always been to generate significant research findings on alcohol, alcoholics, and alcoholism, and to provide education, service, and information dissemination to the world on those topics. ${ }^{\mathrm{I}}$ In fact, the development of alcohol studies as a specific discipline can be traced almost in parallel to the growth and development of the Center of Alcohol Studies.
\end{abstract}

\section{The Section of Studies on Alcohol at Yale (1938-1962)}

In 1943 the Center of Alcohol Studies had its formal baptism as the Section of Studies on Alcohol within the Laboratory of Applied Physiology at Yale University. Alcohol research had already begun at Yale's Laboratory of Applied Physiology in the early I 930's under the combined directorship of Howard W. Haggard and Yandell Henderson. The first volume of the Quarterly Journal of Studies on Alcohol (the bimonthly Journal of Studies on Alcohol since I 975) was published in I 940.

E. M. (Elvin Morton) Jellinek arrived in I 943 as Director of the Section and reinforced the research team's role at Yale. Jellinek's work with Norman Joliffe on the "Study of the Effects of Alcohol on the Individual," a review of the literature, provided the seeds of today's modern library at Rutgers.

The literature review was started in 1938 under the auspices of the Research Council on Problems of Alcohol, with Jellinek as executive director. It was a unique attempt to identify, translate when necessary, and abstract selected portions of the world's scientific literature on alcohol. Known as the Classified Abstract Archive of the Alcohol Literature

* Grateful acknowledgment is extended to John A. Carpenter, Marilyn Carpenter, Mark Keller, Penny B. Page and Adeline Tallau for their help in researching material for this manuscript.

' Nathan, Peter E. "Reports from the research centres - I. Rutgers: the Center of Alcohol Studies." British Journal of Addiction. 82: 833-840. 1987. 
(CAAAL), the index of 1029 original subject headings used a punched card manual retrieval system. ${ }^{2}$

Jellinek also brought his research staff from the New York Academy of Medicine to Yale, and the original Documentation and Information Divisions of the Section of Studies on Alcohol were put into place at that time. ${ }^{3}$

National requests for research information began to move efficiently through the Section's Information Division, which developed a symbiotic relationship with the Quarterly Journal of Studies on Alcohol. The staff of the Information Division continued to collect, index and abstract the international alcohol literature; the abstracted results were added to the CAAAL, and each issue of the Quarterly Journal featured a section of selected abstracts as a current awareness service for its readers. The Information Division was also able to provide tailored subject bibliographies to its clientele, using the CAAAL as a finding aid. ${ }^{4}$

Mark Keller, Managing Editor and then Editor of the Quarterly JournallJournal of Studies on Alcohol from 1950 through 1976, oversaw the continuous process of identifying, processing and disseminating alcohol studies information. In 1972 he outlined a model of a special library using the Library-Documentation-Information-Publication Division of the Center of Alcohol Studies as his example. Here,

". . . the specialist documentalists or information scientists . . . process 'the literature,' convert it into the classified informational bits, and, on request from anywhere, provide very specific answers to most specific questions, mostly in the form of bibliographies and photocopies of abstracts." 5

Yet there was not a distinctly separate library at Yale until some time in I 958, and that library did not absorb the information responsibilities of Keller's multifaceted Information Division until well after the Section, now known as the Center of Alcohol Studies, moved to Rutgers University in 1962 .

= Page, Penny B. "The origins of alcohol studies: E. M. Jellinek and the documentation of the alcohol research literature." British Journal of Addiction. 83: I095- I I03. 1988.

"Keller, Mark. "Mark Keller's history of the alcohol problems field." The Drinking and Drug Practices Surveyor. No. I 4: I, 22-28. 1979.

"Jellinek, E. M. "The Abstract Archive of the Quarterly Journal of Studies on Alcohol." Quarterly Journal of Studies on Alcohol. 2: 2 I6-222. I 94 I.

"Keller, Mark. "A special-library information-center model for a societal-problem ficld." Pp. 12 I-I 29. In: Israel Society of Special Libraries and Information Centers. ISLIC International Conference on Information Science, Tel Aviv, 29 August-3 September, 1971 : proceedings. Vol. I. Tel Aviv: National Center of Scientific and Technical Information; 1972. 
We know that by March 1959 the Yale Center had designated a separate physical space in its headquarters for a library. The library's primary responsibility was to serve as a departmental information center. The fledgling library contained bound volumes of 9 I periodicals dealing primarily with alcohol, over 75 file boxes of material published by regional organizations dealing with alcoholism and alcohol abuse, and additional books, reports, and reprints on subjects, other than alcoholism, related to beverage alcohol. ${ }^{6}$ In support of the work of the Information Division, Esther Henderson initiated an effort to collect full text copies of every document cited in the Classified Archive. ${ }^{7}$

Most of the books had been acquired to support the course work of the Summer School of Alcohol Studies, which held its first session in I 943 and continues to run every summer. (The Summer of I 990 will bring three separate sessions of this continuing education program to the Rutgers New Brunswick campus: the I 990 Summer School of Alcohol Studies, the I 990 New Jersey Summer School of Alcohol and Drug Studies, and the I 990 Advanced School of Alcohol and Drug Studies.)

Additional monograph material in the collection included review copies of books highlighted by the Quarterly Journal. Further library collection development efforts do not appear to have been made. However, there was now one location where all the diverse items identified by the Documentation Division could be organized, stored, and made available to the visiting researcher. The new library was also able to provide copies of the items abstracted in the CAAAL via phone or mail request. Adeline Linton was the first to supervise the collection in its new format.

The Center of Alcohol Studies at Rutgers (1962-1971)

In 1962 the Center of Alcohol Studies moved to the New Brunswick campus of Rutgers University. This move was funded with support from the National Institute of Mental Health and the Christopher D. Smithers Foundation. Selden D. Bacon, Director of the Center at Yale since Jellinek's departure in I 950, continued in that role at Rutgers. ${ }^{8}$

The Center's Information, Publication and Documentation offices, in-

${ }^{6}$ Bacon, Selden D. "Communication of research: role of the Yale Center of Alcohol Studies." Alumni Newes of the Yale Center of Alcohol Studies. I 5: 1-3. I 959.

7 Bacon, Selden D. "The McCarthy Memorial Collection in 1971 ." Quarterly Journal of Studies on Alcohol. 32: 472-477. $197 \mathrm{I}$.

${ }^{8}$ Milgram, Gail G. "The Summer School of Alcohol Studies: an historical and interpretive review." Pp. 59-74. In: Strug, D. L., Priyadarsini, S. and Hyman, M. M., eds. Alcohol Interventions: Historical and Sociocultural Approaches. New York: The Haworth Press; 1986. 
cluding the library, were transferred to what is now the headquarters of the Methodist parsonage on Easton Avenue in New Brunswick.

Librarian Adeline Tallau arrived in June of I 962 and discovered the Yale library distributed among various rooms of the old house on Easton Avenue, with most of the journals and non-book materials packed away in boxes in the attic. An additional number of biochemical journals were stored at the offices of David Lester and Leon Greenberg on Busch campus in Piscataway. Books from the Yale Summer School were scheduled to arrive at a later date. Very little of the monograph material was cataloged, and there was only a partial printed list of available journal titles.

Tallau reports that her first bit of business as Librarian was to requisition a typewriter, a Kardex, and an electric eraser. She then had to immediately organize the collection for the i 962 Summer School of Alcohol Studies, which was held at Douglass College that year. A portion of the library was moved to Douglass Campus in New Brunswick for a six-week period and then returned to Easton Avenue.

A second shipment of books soon arrived from Yale, namely, the Anne Roe collection of textbooks on alcohol education. By this time Tallau had managed to set up a system of shelving in the living room of the Easton Avenue house. She had also inventoried the boxes of journals stored in the attic, and produced a holdings list. Monograph material was being systematically cataloged and entered into the Rutgers University Union Catalog.

In I 964 the Rutgers Center of Alcohol Studies moved at last to Christopher D. Smithers Hall on Busch Campus, with the formal dedication occurring on April 2, 1964. The different divisions were reunited from their temporary offices on the Busch and College Avenue campuses in the spacious new building. Tallau supervised the arrangement of the Library's physical space, the selection of library furniture and permanent shelving, and the transfer of the reorganized collection.9

The Information Division remained the primary resource for alcohol information requests for the public at that time. The Center's Information specialists continued to prepare and distribute subject specific research bibliographies using the CAAAL system, which was maintained in full operation until 1978.

The Library was the organized repository for printed materials, primarily the full text documents identified in the Classified Archive. In I 965 these documents were designated the McCarthy Memorial Collec-

\footnotetext{
9 Adeline Tallau. Rutgers Library of Science and Medicine, Piscataway, NJ. Interview, I March 1988.
} 
tion in honor of Raymond G. McCarthy, one of the Center's illustrious alumni. Center Director Seldon Bacon described the McCarthy Collection in $197 \mathrm{I}$ :

"The Collection is . . the most superb organization of scholarly materials in the field. It is growing. It is useful . . It is a memorial which we are sure would please Ray and in which the contributors and workers may feel a justifiable pride."'o

In I 990 the McCarthy Collection is still growing and still useful. It is the core of the modern Center of Alcohol Studies Library.

The Library was also a place where visitors could pursue their own research in 1964 . The shelves of books and journals, all related in some way to the study of alcohol and alcohol problems, were recognized as an important compilation. The Library continued as a departmental information resource for the Center's faculty and staff.

Adeline Tallau began a Master Catalog of all items collected by the Library for the Journal abstracting service, CAAAL, and the International Bibliography of Studies on Alcohol 1901-I950 (Mark Keller, ed. New Brunswick, NJ: Rutgers Center of Alcohol Studies; I 966). This catalog contains a single first author entry for each item stored in the $\mathrm{Li}$ brary, as well as alcohol-related citations identified but not held at Smithers Hall. With monographs cataloged in the Rutgers University Union Catalog and non-monograph materials listed in the Master Catalog, there was finally a systematic methodology for locating all Library resources. '

Rutgers and NIAAA (1971-1981)

I 970 saw greatly increased national emphasis on alcohol research and policy. Most importantly, the National Institute on Alcohol Abuse and Alcoholism (NIAAA), the federal alcoholism agency created by the Hughes Act, was created in December $1970 .{ }^{12}$ NIAAA began funding the Center of Alcohol Studies, and the work of the Documentation Division was supported specifically through a series of annual grants administered directly to the Division. These grants continued through I 976 ; at

\footnotetext{
10 Bacon, Selden D. "The McCarthy Memorial Collection in 197 r." Quarterly Journal of Studies on Alcohol. 32: 472-477. I97 I.

"Adeline Tallau. Rutgers Library of Science and Medicine, Piscataway, NJ. Interview, I March 1988.

${ }_{12}$ Lewis, Jay. "The federal role in alcoholism research, treatment and prevention." Pp. 385-4OI. In: Gomberg, E. L., White, H. R. and Carpenter, J. A., eds. Alcohol, Science and Society Revisited. Ann Arbor, MI and New Brunswick, NJ: University of Michigan Press and Rutgers Center of Alcohol Studies; 1982.
} 
that time the federal funding mechanism was changed to a sole contract arrangement between Rutgers and NIAAA referred to as the "Cooperative Agreement."

The beginning of the I970s also heralded the arrival of Jane Armstrong as Library Director at the Center. The Library, and the other components of the Documentation-Information Division, began to respond to the new interest from the federal government, and the subsequent reaction of the alcohol research community. One of those reactions was an overwhelming increase of published material in the area of alcohol studies, all of which was routinely forwarded through the Center's abstracting and indexing team and deposited in the Library. In I974, in an effort to streamline a procedure which threatened to become unmanageable, the Documentation Division negotiated with Inforonics (Maynard, MA) to have all abstracts published in the Journal translated into machine-readable tape format. Inforonics had been providing this service for the printed index of the Journal since I 970. This allowed a new flexibility in organizing the information for publication although the tapes were initially stored in Massachusetts and could not be accessed directly by Center staff. ${ }^{13}$

Maintenance of the Classified Abstract could not keep pace with the rapid acquisition of material. The punched card manual system was growing too large and cumbersome for easy manipulation, and in 1978 , CAAAL was closed with nearly 20,000 entries. ${ }^{\mathrm{T} 4}$ The Center Library still holds a complete set of CAAAL cards, as do several other libraries and information centers around the world. It remains a unique resource for retrieving retrospective information on alcohol use and problems, particularly because of the inclusion of foreign language material.

The Journal continued to identify and publish abstracts until i 982 . The Journal of Studies on Alcohol annual index from 1978 through I 982 can be used as a printed extension of CAAAL to identify subject specific alcohol references.

In 1980 the Center experimented with operating a bibliographic database of its abstracted references by loading the Inforonics tapes used for producing the Journal index onto CDC's (Control Data Corporation) CYBERNET network. The database, "Alcohol Information Retrieval Sys-

13 Journal of Studies on Alcohol, Incorporated. Minutes of the Annual Meeting of the Board of Directors on 26 October 1976.

14 Page, Penny B. "The Yale/Rutgers Center of Alcohol Studies." Pp. 50-55. In: Alcohol and other Drug Information Resources: Proceedings of an International Symposium Held in San Diego, CA, March 9-13, 1988 . I a Jolla, CA: University of California, San Diego, Program on Alcohol Issues; 988. 
tem" (AIRS), offered text word and controlled term searching, truncation, a number of sort options, and off-line and on-line printing. Abstracts were included from 1974 forward, and plans were made to enter all abstracts from CAAAL in one retrospective effort. CDC discontinued the project in I98I, however, and efforts to negotiate with other database vendors were not productive. ${ }^{15}$

The Inforonics tapes had also been loaded onto the bibliographic database operated by the National Clearinghouse for Alcohol Information (NCALI), as a result of the "Cooperative Agreement" between the Center of Alcohol Studies and NIAAA. Citations were included from 1976 forward; the Information Division had direct access to this database until I 983 . At that time the file was not commercially available, but in I 988 it was picked up in its current format by BRS Information Technologies as "ETOH_Alcohol and Alcohol Problems Science Database."

Requests for subject specific bibliographies, which had previously been answered using the CAAAL, could now be searched on AIRS or the NCALI file. An outgrowth of the AIRS database was the publication of two series of printed bibliographies on a number of alcohol-related topics. These bibliographies began as printouts on repeatedly requested subjects. "Recent Topics in Alcohol Studies" covered the biomedical literature, and the "Alcohol Bibliography Series" included the psychosocial aspects of alcohol information. The biliographies continue to be maintained by the Library staff in I990, and now serve as the primary means of subject identification for material in the Library's many collections.

In I 98 I NIAAA reevaluated its direct funding of the Information Services at the Center of Alcohol Studies and the "Cooperative Agreement" was terminated in 1983 . Contributions to the NCALI database discontinued, as did the Center's on-line access to the database.

\section{The Library from $1981-1990$}

Again, the beginning of a decade brought significant changes in the Library's evolution. Throughout the 70's Jane Armstrong had operated the Library as a component of the Center's larger Information Division, specifically as an organized collection to house the results of that Division's activities. Direct in-house requests for information were fielded through the Library, while the Information Office responded to phone and mail demands. Armstrong continued to arrange special services for the students and faculty of the Summer School of Alcohol Studies.

Penny Page became Library Director in I98 I. The funding cuts re15 Ibid. 
sulting from the termination of the "Cooperative Agreement" required a new approach to traditional information services at the Center of Alcohol Studies. The Journal was forced to discontinue its abstracting services and the Information Division was disbanded. In I 983 Rutgers University agreed to continue financial support of the Library and Library personnel (two professional librarians and two library assistants) and the Library was integrated into the Rutgers University Library system as a Science Branch Library.

Today, in I990, the Library remains the primary point of access for information requests through the Center of Alcohol Studies. It serves members of the Rutgers community and the state of New Jersey, as well as visitors from around the world who travel to Smithers Hall to use one of the most comprehensive alcohol studies libraries in existence.

Phone and mail contacts still outnumber those of in-house visitors; the Library routinely offers copies of its expanded bibliography series to replace the services once provided by CAAAL and the two databases operated by the staff of the Information Division. Librarians still perform database searches when appropriate, using a number of commercially available files which span the multidisciplinary subjects relevant to alcohol and other drug literature. Since I 988 , citations in the bibliography series (now numbering over $\mathrm{I} 20$ separate topics) have also been entered into an in-house database maintained entirely by Library staff. The file holds over I I , OOO records which can be searched directly using controlled term and/ or text word retrieval.

Patrons use the bibliographies to directly access material from the McCarthy Collection (over 35, Ooo documents), monographs on the Library shelves (over 8,000 ) and articles from some 200 journal titles. The $\mathrm{McC}$ arthy Collection now contains reprints of journal articles, conference proceedings and government documents which are considered particularly important to alcohol studies research. An additional reprint collection (20,000 documents) holds materials of the same format deemed less significant as original research contributions. Material formats from both reprint collections also include dissertations, theses, separately authored book chapters, substantive pamphlets, unpublished papers, and subject bibliographies. The monograph collection is fully catalogued and entered into the Rutgers University Library on-line catalog.

Several unique collections have been donated to the Center of Alcohol Studies Library as a result of its history and reputation in the field. In I 976 the Library received the Ralph G. Connor Alcohol Research Reference Files (CARRF) from the estate of Dr. Connor. This collection, 
maintained since I 960 by Dr. Connor at Eastern Washington State College, is an archive of English language research instruments (questionnaires, interview schedules, surveys, etc.) that have been used to research aspects of drinking behavior and alcoholism. ${ }^{16}$ The CARRF is now updated by Library staff and numbers over 500 instruments. There is an annotated index (author, title, subject) to the collection, which was revised by Penny Page in 1987.

In I 98 I the Ohio Historical Society donated a large number of foreign language temperance materials first collected by the Anti-Saloon League of America. These materials include tracts, monographs, periodicals and yearbooks of United States foreign language temperance groups from I 900 through I 960 . The collection complements the existing archive and manuscript collections at the Center, which contain historical records of many institutions in the alcohol field, including a quantity of English language temperance papers.

The National Association of Lesbian and Gay Alcoholism Professionals (NALGAP), in I 987, requested Center Library space to house their archival collection of literature on chemical dependency and homosexuality. The NALGAP Library is a unique resource for the fugitive literature important to that population, and is being continually updated by bibliographers at NALGAP.

The National Council on Alcoholism bequeathed its institutional library to the Center of Alcohol Studies in I988. Grant funds from the New Jersey State Library were received in I 989 to incorporate this uninventoried collection into the Library's holdings.

The Library and the Center's Division of Education and Training worked together with the State of New Jersey's Department of Higher Education to design the New Jersey Alcohol/Drug Resource Center and Clearinghouse, which began its activities in 1988. The Resource Center is administered jointly by Penny Page and Gail G. Milgram, Director of the Center's Division of Education and Training. Two Clearinghouse goals are to develop core collections of alcohol/drug education, treatment, and prevention materials and to disseminate information on those topics to residents of the State of New Jersey.

This state-funded program allows the Library to round out its comprehensive research collection with material on alcohol and other drugs appropriate for the general public and the educational community. For the

\footnotetext{
${ }^{16}$ Ralph G. Connor Alcohol Research Reference Files (CARRF) Index. New Brunswick, NJ: Rutgers Center of Alcohol Studies, 1976.
} 
first time, the Library is collecting curricula and programs on alcohol/ drug education and prevention issues, as well as distributing free and lowcost information to the public in the form of pamphlets, resource guides, and bibliographies. The Clearinghouse is also developing a media collection, another first in the Library's collection development efforts. Valerie Mead is the Librarian in charge of this special service.

The Center of Alcohol Studies Library is currently planning a new facility in the Brinkley and Adele Smithers Hall, the addition to Smithers Hall which was generously funded by Brinkley Smithers and Rutgers University.

It is once again the beginning of a new decade, traditionally a time of change for information services at the Center of Alcohol Studies. The Library is now preparing to examine its expanding role at the Center, and to define and plan strategies to meet the information demands of its diverse clientele in its new physical space. As regards the scope and potential uses to which the Alcohol Studies collection can be put, we still feel as Mark Keller did twenty years ago, that

"what you need is to come and spend some time in our library."

17 Keller, Mark. "A special-library information-center model for a societal-problem field." Pp. I 2 I-129. In: Israel Society of Special Libraries and Information Centers. ISLIC International Conference on Information Science, Tel Avic, 20.August-z September, I97 I: Procedings. Vol. 1. Tel Aviv: National Center of Scientific and Technical Information; 1972. 